\title{
The Main Functions and the Landscape Specialty of the Development of Remote Village
}

\author{
Gui-ju Lv ${ }^{1}$, Da-liang Liu ${ }^{3}$, Ming-yuan Zhao ${ }^{2}$, Lan-yong Zhao ${ }^{2,}$ * \\ ${ }^{1}$ College of Horticultural Science and Engineering, Shandong Agricultural University, Taian, China \\ ${ }^{2}$ College of Forestry, Shandong Agricultural University, Taian, China \\ ${ }^{3}$ College of Art, Shandong Jianzhu University, Jinan, China
}

Email address:

sdzly369@163.com(Lan-yong Zhao)

${ }^{*}$ Corresponding author

\section{To cite this article:}

Gui-ju Lv, Da-liang Liu, Ming-yuan Zhao, Lan-yong Zhao. The Main Functions and the Landscape Specialty of the Development of Remote Village. International Journal of Environmental Protection and Policy. Vol. 6, No. 1, 2018, pp. 14-18. doi: 10.11648/j.ijepp.20180601.13

Received: March 28, 2018; Accepted: May 3, 2018; Published: May 10, 2018

\begin{abstract}
At the beginning, this article defines the meaning of rural landscape which is based on the space of rural area and is the organic unity of economic production, residence life, natural habitat, spiritual culture and pattern. In this article, I will point out the connection of these five parts and analyze its necessities and functions. I chose five rural villages as the objects of this study. The characteristics of rural landscape corresponding to different main functions of mountain villages are discussed, and the relationship between rural landscape characteristics and the function of rural main body is established. The village landscape function design based on landscape characteristics is studied with the flower brocade village as an example, which provides technical support for the development of mountain villages.
\end{abstract}

Keywords: Rural Landscape, Theme Features, Landscape Specialty, Functional Orientation

\section{The Definition of Rural Landscape}

\subsection{The Meaning of Rural Landscape}

Sol, the American geographer considered that 'rural landscape is the interdependence of humanity, society and economy', or 'the totality of society, humanity and economy within a rural area's [1]. To the construction of rural villages, the sound development should not only connect to the sense of beauty of space and figure or the splendid economic growth indexs [2].

Rural landscape design is built on rural land space and objects by the economic production, live and natural habitats, spiritual culture, landscape form mutual fusion and form an organic unity of five parts [3-4]. Rural landscape is also a complex of cultural landscape and natural landscape. Besides, human interference intensity is relatively low, the natural property of landscape is strong, and natural environment occupies the main body in the landscape.

\subsection{The Intension of Rural Landscape}

In terms of research scale, villages can be divided into village, village and houses [5]. House is the space that villagers daily life work, is affiliated residential courtyard, is the smallest group of life, is in the village the villagers live environment scale, mainly the villagers living life space, village field is containing the villagers live environment and the surrounding farmland forest land. Of history or habits of life and production of a village which is formed by the geographic space, general with roads, rivers, mountain ridge or the actual farmland and ShanChang is bounded, including boundary can use. The village space in the mountainous area is often less than $1 / 10$ of the range of the village. In this paper, the village is not specifically referred to as the village domain.

In terms of concept, including form, ecological landscape, usability and rationality, usability to rural landscape, landscape is reflected in the living life and economic production of two parts, so the rural landscape includes economic production, live and natural habitat, spirit culture and landscape form. The five aspects of the rural landscape complement each other, and the living and economic production is the main function of the rural landscape, which influences each other. Natural habitat is the material and 
energy source of villagers' life and production, and is the basis of rural landscapes [6].

The five aspects of the rural landscape complement each other, and the living and economic production is the main function of the rural landscape, which influences each other. Natural habitat is the material and energy source of villagers' life and production, and is the basis of rural landscape. Spiritual culture is the cultural thought formed by the accumulation of the villagers in the production of life, which is integrated into people's residential life landscape and production landscape. Natural habitat and rural culture influence the other three aspects of rural landscape. The pattern form is the external form that is diffracted by the harmonious coexistence of the villagers in the life and production, which is the external representation of the rural residential life, economic production, natural habitat and spiritual culture.

\section{The Main Functions of Rural Area}

\subsection{The Basis for Determining the Function of Rural Subjects}

Rural economic production, residential life, natural habitat, spiritual culture and pattern form contain a lot of content. The economic production landscape includes traditional agricultural landscape and other industrial landscape, and the traditional agricultural landscape is the landscape formed in the traditional agriculture, such as terraces and forestry in the mountainous areas of Shandong.

A variety of industrialization of the rural, the rural rich industrial session of landscape types, such as: modern agriculture, organic agriculture, leisure agriculture, agricultural estate, the passenger business, aquaculture, handicrafts and the 123 productive landscape in the development of industrial convergence. Rural landscape living life connotation of landscape space are closely related and the villagers living space, living, to provide for br, meet the demand of living place is villagers' residences, yard, street, alley and clearing. The space and objects formed are the concrete manifestation of residential life landscape: residential landscape, courtyard space, street space and assembly spaces Natural habitat, rural landscape is the material basis for the country to survive life, also is the important feature of the countryside differs from cities, including topography, river water, plants, and animals, soil, stone, climate, temperature, wind direction. Traditional natural habitat is a healthy ecosystem, relatively low productivity, villager's ability to change the natural environment is limited, the villagers and the adaptation of the natural environment formed by the villagers a harmony with the natural habitat of the ecosystem: blue sky, green water, healthy, fresh flowers and plants, trees and carefree villagers compose the health of the country. Influence of the new rural construction on the ecological environment is the most obvious, ignore the maintenance of the ecological environment, causing the destruction of the ecological environment, will eventually lead to the rural sustainable development or not healthy development or no staying power. Spiritual culture includes two parts, one for the intangible cultural heritage, is refers to the various national patrimony of the people, and people life is closely related to the various manifestations of traditional culture, such as folk activities, performing arts, traditional knowledge and skills, as well as the related equipment, material, handmade products, etc.) [7-9], the other intangible cultural forms related cultural space [8]. Form is also important connotation of rural landscape, landscape form is expressed in the form of external form in the countryside, small to material combinations, door style, decorative pattern, big to buildings, roads, village landscape form.

The main functions of the countryside are based on the five aspects of rural landscape, and the five main functions are determined: residential life, artistic activities, spiritual culture, economic production and natural habitat. The main function of each village corresponds to the function orientation. The functional orientation of residential life is a series of functions derived from serving villagers' residence and life: education, medical treatment, children's play, fitness, living, activity space, etc. The function orientation of art activities is to provide the functions related to art: art exhibition, art sketch, art creation, artist design studio, art study and so on. Economic production function orientation is the country's economic source mainly based on agriculture, forestry or handicraft industry, function involves two aspects, first, the direct economic function of handicraft industry in the agriculture, forestry, forestry and agriculture produce indirect economic function of tourism handicraft industry. Spiritual culture function orientation is key protection area, the historical and cultural remains relatively concentrated, distinct regional characteristics of residential courtyard, assembly, cultural space, the main roadway and the performing arts, folk activities, artifacts, diet dialect. The area is forbidden to build or expand buildings, and to protect the materials, color, height and volume of the building, to limit the content of human activities. The function orientation is to protect the natural resources of the natural habitat of important areas, points to ban development area and limited development area [9-11], human activity is not allowed in development area shall be prohibited from entering, limited development area is on the basis of protecting natural reasonable design and the function of the related activities.

\subsection{The Necessity of the Rural Areas'Main Functions}

It is unrealistic to ask for a rural landscape to be optimal in every aspect of economic, social, ecological and cultural functions. For example, rural agricultural productivity is maximized, which will inevitably affect the ecological function and cultural function of the countryside. The main appeal of cultural function may affect the life function and economic function of the countryside. The comprehensive function of rural landscape, therefore, refers to the country as a whole range of comprehensive, regional between complement each other, and not require rural areas must meet all of the 
landscape function requirements. In various types of function of one aspect of the landscape can be more prominent landscape with different functions and purposes, the landscape to achieve the overall balance.

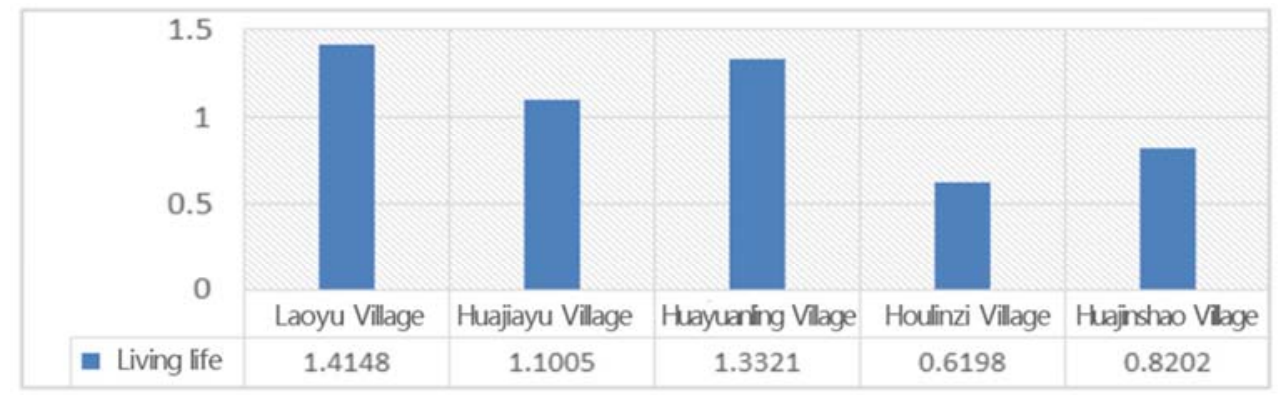

Figure 1. Evaluation of the function of rural living life.

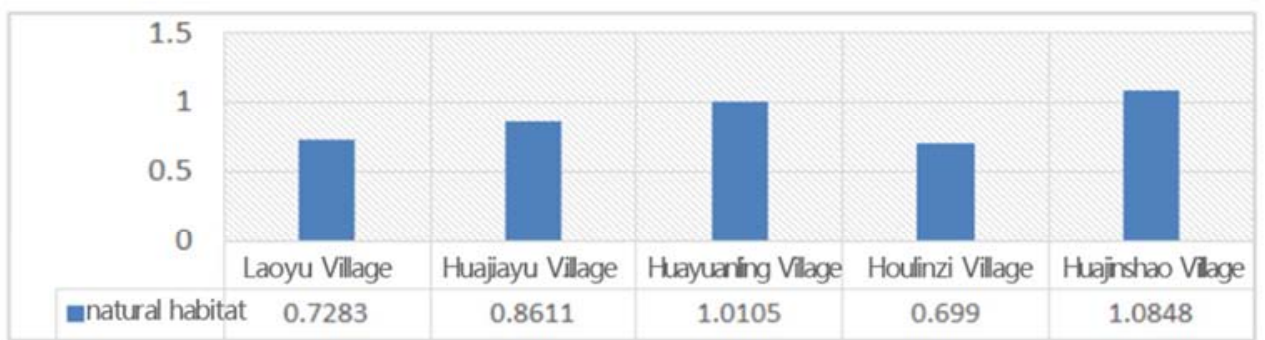

Figure 2. Evaluation of the function of rural natural habitat.

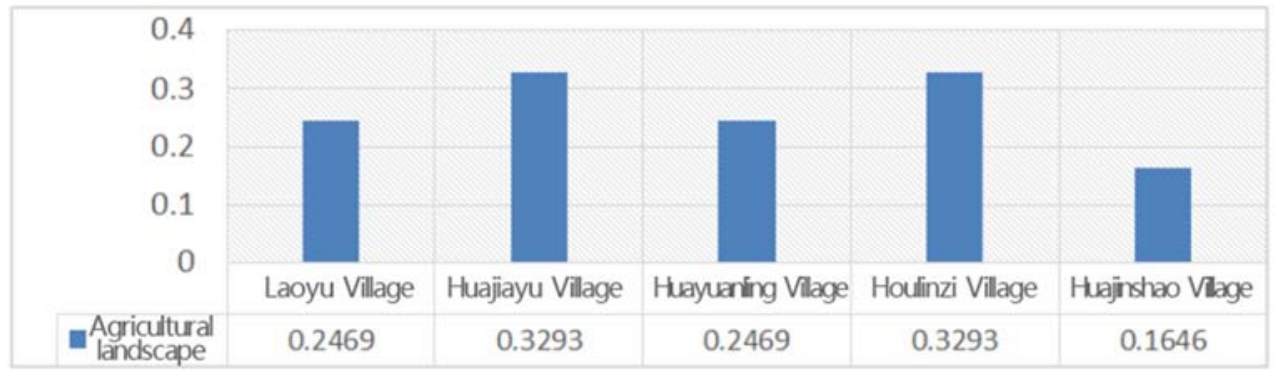

Figure 3. Evaluation of the function of rural Agricultural landscape.

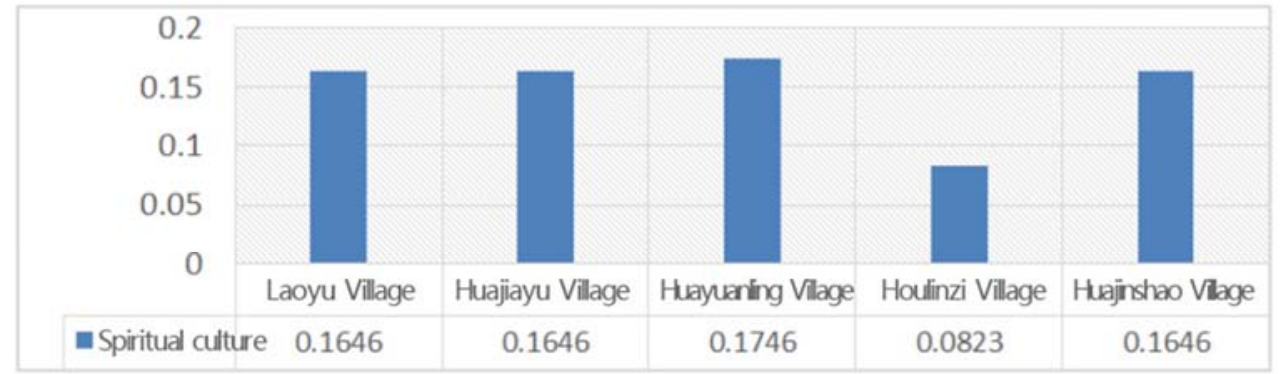

Figure 4. Evaluation of the function of rural Spiritual culture.

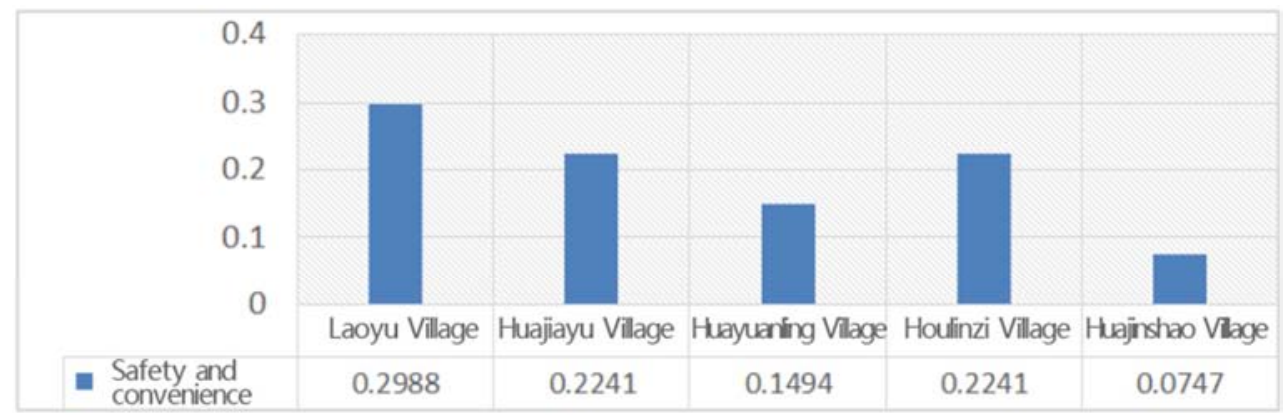

Figure 5. Evaluation of the function of rural Safety and convenience. 


\section{Rural Peculiarity}

Choice of jinan XiYing town five representative adjacent mountain country village as the research object, the country reflect the common problems of the mountainous country, analysis the present situation of the research findings are country representative. To live in the countryside, artistic atmosphere, spirit, culture and economic production, the natural habitat of five aspects to analyze data chart (figure 1 figure five) facilitate intuitive comparison and analysis. Through the analysis and comparison of landscape characteristics, the unique characteristics and individualized temperament of every village in life production ecological form and culture are determined.

\subsection{The Rural Quality of the Main Function of Art}

Rural art into the main body function refers to itself based good country use art means to enhance the value of the charm of country and industry, actively attract artists or spontaneous art exhibitions and rural reform. The main body of the village art is the countryside, which is the need of the development of the country, and the village takes the art as the means to attract the active behavior of the urban crowd, which is basically the continuation of the movement of the whole village. Artistic? What kind of country suitable for the development of the country, and through a comprehensive evaluation and learned that 16 of the rural landscape in meiyukou village: the most suitable for the development of art in the rural landscape is rich, the terrain ups and downs is bigger, has a wealth of three hyperopia scene, but different angles look up, vertical peace, make the person with the mountain and village with different scale distance between Angle of perception. Natural habitat is good, the nature is the art of the best venues and source of all things a kaleidoscope of growth over time and with the weather varies with location and harmonious beauty, people in such a natural environment can be more easily broke out many good ideas, purify the mind, body and mind. Agricultural landscape is good, the country's economy is mainly agricultural, no what is rural agriculture, so the artistic also inevitable requirement of rural agricultural field characteristic or characteristic agricultural resources. Living atmosphere is good, life is the source of art, life in the rural simplicity, contains extensive and profound Chinese agriculture civilization and wisdom, local-style dwelling houses building and building, street, in the form of winding vicissitudes of life, the sunshine chatting villagers living and so on are vivid life scenes and historical imprint. These are the rural qualities needed to develop the artisanal countryside.

\subsection{The Rural Peculiarity of Living}

Living and living as the main function of the countryside refers to a series of functions derived from serving villagers' living and living: education, medical treatment, children's play, fitness, living, activity space, etc. The village itself has the localization of the most important characteristic is location: external and urban main road right distance, distance is too close to urban trunk road, lost the hush of the country, too far, the villagers and external interrelated inconvenience, it is generally believed walking a distance of 20 to 30 minutes is appropriate, can guarantee the mountain country is quiet and convenient for transportation of villagers and outsiders. Distance with other villages also wants appropriate, through interview and more different rural villagers with planning theory as the comprehensive function of the grass-roots village and other villages distance is about 1 five minutes walking distance in 1200 meters, 1200 meters. Moreover, the terrain of the village is relatively flat, especially the line and slope of main street, which requires simplicity and gentleness. It also needs the compact and cohesive space in the village, which is convenient for the use of comprehensive functions and the concentration of people.

\subsection{The Rural Peculiarity of Economic Manufacture}

The rural economic sources in the rural areas of lu zhongshan are agricultural, and the income of agriculture can only satisfy people's need for food and food. This is because in the terrain slope, the centralized scarce farmland of large area, large slope topography also bring difficulty to the mechanization of farming, soil barren mountains and water is not enough also bring serious hinder agricultural revenue. The good climate in mountainous area is the most important condition for the development of modern agriculture in organic agriculture, so it is feasible for rural organic agriculture + experience agriculture in Shandong mountain area.

Able to develop this kind of function of village has two characteristics, one of, have larger area and concentration of agricultural land, this is the development of agriculture must conditions, the other of the top two small space, it is to let a person experience the rural everywhere have the key to agriculture, the third has a rich legacy of history and agricultural facilities and technologies, such as stone mill, the mill, hoe and so on. This is the inheritance of the history of agriculture.

\subsection{The Rural Peculiarity of Spiritual Culture}

Research within the scope of the country's intangible cultural heritage content mainly in shandong folk opera, local traditional festival, folk temple fair and religious activities, the content as the village population decline and loss are mostly gone. If you want to develop the spirit of culture as the main body function of the countryside, it should has the characteristics of localization of has two aspects, one is that within the scope of the region, compared with other country, the country's non-material culture assessment is the highest, in this research, geographical scope is referring to the old valley village, garden ridge, 16 valley, ridge, spend gold Shao, in the five villages of non-material cultural research, garden ridge, the highest evaluation, not only for garden ridge same folk drama and other villages, traditional festivals and folk temple fair, and the village now has unique customs: each in turn to worship fairy virgin empress, each for one year, namely turn 
"empress". In addition, the villagers in the garden village are very confident in their own villages, and advocate the concept of "the gentleman without dispute" and "enthusiasm for others". This is undoubtedly influenced by the profound rural culture. Secondly, it has good residential building and street space and natural ecological environment, which is the material embodiment of the spiritual culture of the countryside for thousands of years.

\subsection{The Rural Peculiarity of Natural Habitat}

The local characteristics of the rural areas with natural habitat as the main function are of course the distinctive features of the rural natural elements compared with other rural areas. Flowers kam Shao is five rural natural habitat evaluation of the highest in the country, mainly because of rural ecosystem of the natural environment and the characteristic, flowers kam Shao mountain full coverage and high mountain topography, plant richness, mountain plants also have stronger richness and the shadow of spring summer autumn leaves Holly the appreciation of the four seasons. And long since ancient times the mountain is a large flower, flower color is yellow, named golden flowers, in the long have a flower on the top of the mountainside and one old Wells, the villagers went to the mountains for water and then take her home "Shao", the name of the country will be the three most important elements in the natural environment: mountain, plant and water together, this also from another side, reflects the flowers gold Shao villagers respect of nature, thus in the production of life close harmonious relationship between man and natural holder. Natural habitat is suitable for the development of health related industries, and provides a variety of residential options for China's growing aging population.

\section{Conclusion}

Small mountain village, less population, relatively scattered, separate for each country for planning to achieve rural comprehensive function is obviously not possible, look from the global tourism social background and it won't work, so the investigation summarizes the landscape character of each country, and then deduces the country's main body function and function orientation, then several similar geomorphic unit and position distance is relatively close, the historical and cultural traditions similar separate villages are merged into one big country group unified planning and construction. To establish a reasonable landscape pattern, planning and design a variety of form and function of rural landscape, strengthen the rural group of tourist attraction, improve the lives of the villagers, unified PeiJian appropriate public service facilities and infrastructure, promote the coordinated development of rural society economy and culture.

\section{References}

[1] Huang Baorong, Zhang Huizhi, Wang Xuezhi. The Impact of Urban Expansion on Natural and Agricultural Landscape of Beijing's Urban-Rural Fringe-Taking Three Towns of Changping District as an Example. [J]. Acta Ecologica Sinica, 2014, 34(22):67five6-6766

[2] Mi Manning, Zhang Zhenxing, Li Wei. A Study on the Diversity and Development of Domestic Productive Landscape [J]. Ecological Economy 201 five, five:196-199

[3] The Southern Provincial Capital of the Ecological Economic Zone of Scientific Development Expert Group, Gao Huanxi etc. Suggestions on Actively Promoting the Scientific Development of the Ecological Economic Zone in the Southern Provincial Capital (1) [J]. Journal of Shandong Academy of Governance. 2013, 4:1-8

[4] Wang Yanglin, Han Dang. Ecological Planning and Design of Agricultural Landscape [J]. Chinese Journal of Applied Ecology. 2000, 2:26five-269

[5] Xie Hualin, Liu Liming, Zhao Yingwei. Studies on the Indicator System of Rural Landscape Evaluation and Evaluating Method [J]. Research of Agricultural Modernization. 2003, 24(2):9five-102

[6] Shen Mingrui, Zhang Jingxiang. China's Rural Transformation and Revival in the Context of New Urbanization [J]. City Planning Review. 201 five(01):42-47

[7] Hu Ruiyi, Chen Dongtian, Yu Caiyun, Zhang Ying. Research on Design of Rural Landscape on Low-cost Concept [J]. Shandong Forestry Science and Technology. 2017(08)

[8] Liu Zhihao, Jin Qiming. Study on the Types of Rural Cultural Landscape and Its Evolution [J]. Journal of Nanjing Normal University (Natural Science). 1999, 22(4):121-128

[9] Han Yue, Tian Dafang. Construction of Evaluation Index System of Rural Tourism Landscape Attraction [J]. Shanxi Architecture. 2017(01)

[10] Shao Juehan, Liu Binyi. Analyzing the Visual Perception of Rural Landscape [J]. Chinese Landscape Agriculture. 2016(09)

[11] ZhangXiaoyan. Rural Landscape Construction on the basis of "Beautiful Village"[J]. Art Observation. 2017(08) 